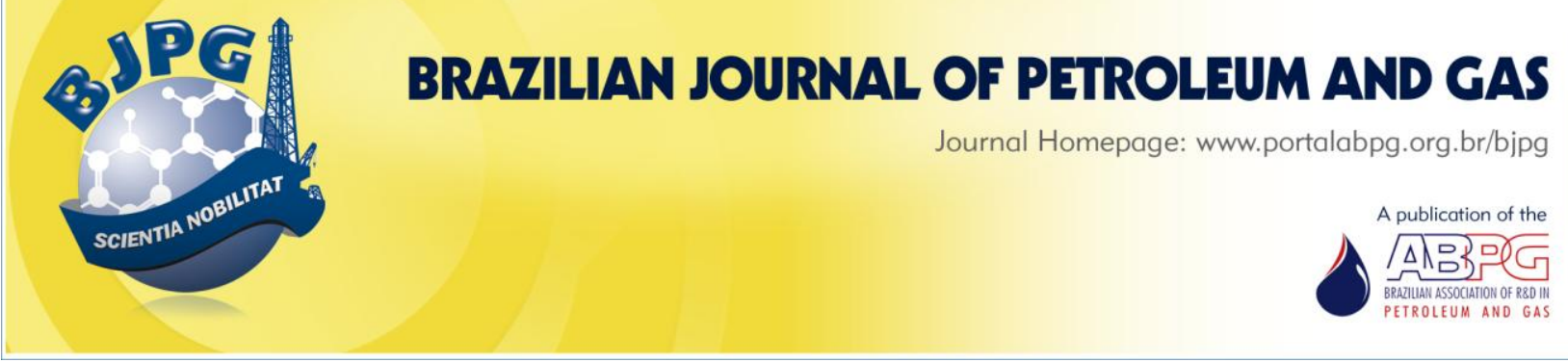

\title{
WAG PROCESS DESIGN - AN UPDATED REVIEW
}

${ }^{\text {ab }}$ Zahoor, M. K. ${ }^{1}$; ${ }^{\text {D }}$ Derahman, M. N.; ${ }^{\text {b }}$ Yunan, M. H.

a Department of Petroleum and Gas Engineering, University of Engineering and Technology, Lahore, Pakistan

${ }^{b}$ Department of Petroleum Engineering, Universiti Teknologi Malaysia, Skudai, Johor, Malaysia

\section{ABSTRACT}

The design and implementation of water-alternating-gas (WAG) process in an improved and cost-effective way are still under process. Due to the complexities involved in implementing the process and the lack of information regarding fluid and reservoir properties, the water-alternating-gas process has not yet been as successful as initially expected. This situation can be overcome by better understanding the fluid distribution and flow behavior within the reservoir. The ultimate purpose can be achieved with improved knowledge on wettability and its influence on fluid distribution, capillary pressure, relative permeability, and other design parameters. This paper gives an insight on the WAG process design and the recently developed correlations which are helpful in incorporating the effects of wettability variations on fluid dynamics within the reservoir.

\section{KEYWORDS}

WAG process; water alternating gas; wettability; capillary pressure; relative permeability

\footnotetext{
${ }^{1}$ To whom all correspondence should be addressed.

Address: Department of Petroleum and Gas Engineering, University of Engineering and Technology, Lahore, Pakistan e-mail: mkzahoor@uet.edu.pk, mkzahoor@yahoo.com doi:10.5419/bjpg2011-0012
} 


\section{INTRODUCTION}

Generally, water injection is the chosen recovery technique in the case of water-wet reservoirs, and gas injection is similarly preferred for oil-wet reservoirs. However, water-alternatinggas (WAG) processes give better recovery than injecting gas or water alone by utilizing the advantages of both gas and water injection at the same time (Freistuhler et al., 2000; Soares, 2008). When water and gas injection are implemented simultaneously, the front stability increases, resulting in better sweep efficiency (Dehghan et al., 2009; Hyne, 2001). The WAG process provides higher microscopic gas displacement efficiency and better macroscopic water sweep efficiency, which leads to better displacement and increased recovery when compared to gas or water injection techniques (Christensen et al., 1998, 2001; Dehghan et al., 2009; Rouzbeh and Larry, 2010; Sohrabi et al., 2004).

Reviews published by Christensen et al. (1998, 2001) show that the predicted incremental recovery (over waterflooding) obtained by the implementation of WAG projects ranges from 2.0 $\%$ to $19.6 \%$, with most cases lying between $6 \%$ and $16 \%$. In addition, the reviews show that the actual observed incremental recovery on field scale declines by a factor of almost $40 \%$ on average with respect to the predicted values, due to productionrelated problems. The recovery factors mentioned in these reviews, however, can be increased by proper design and implementation of the WAG process.

Significant efforts to increase recovery rates by modifying the WAG process have been made (Christensen et al., 1998; Gorell, 1990; Jianwei et al., 2008a,b; John and Reid, 2000; Prieditis et al., 1991), but most of them are at laboratory scale and need to be further analyzed critically in order to

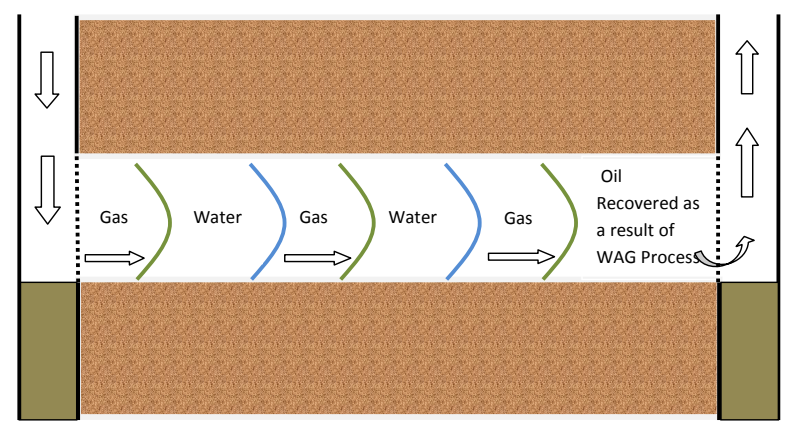

Figure 1. Schematic diagram of the WAG process. offer similar promising results on field scale. The difference in results between experimental investigations and practical implementation on reservoir scale usually arises from the fact that the cores are not generally true representatives of the reservoir. This occurs due to the fact that core samples represent the reservoir properties on localized scale and moreover their properties (wettability, permeability, etc.) are also altered during drilling and various core handling procedures (O'Carroll et al., 2005; Shedid and Ghannam, 2004).

\section{WAG PROCESS CLASSIFICATION}

A typical WAG process is schematically shown in Figure 1. A number of classifications are available, based on the types of fluid involved and the manner in which they are injected, but, in general it can be divided into miscible and immiscible displacement process (Christensen et al., 1998, 2001; Ho and Webb, 2006; Jensen et al., 2000; Jianwei et al., 2008b, Lo et al., 2003, Raj et al., 2010).

In the miscible WAG process, the injected gas is miscible with the reservoir oil under the prevailing conditions (Arne and Elisabeth, 2007). Miscibility can be further classified as first-contact miscibility, when the gas is miscible as it becomes in contact with the oil, and multi-contact or dynamic miscibility, in which miscibility is achieved with time as displacement continues (Al-Shuraiqi et al., 2003; Ho et al. 2006; Willhite, 1986). Partial miscibility may also exist within a reservoir in which the injected gas is not completely miscible with oil and also retains its free state (Latil 1980; Willhite 1986). Miscibility of gas provides an additional advantage of decreasing oil viscosity, thereby resulting in mobilization of trapped oil ganglia during later production stages.

In the immiscible WAG process, the injected gas is not miscible with the reservoir oil and it displaces the oil while maintaining its gaseous phase, with a front between the two phases (Fanchi, 2004; Latil, 1980; Willhite, 1986). Further classification of WAG process is given below, depending on the injection technique used in the process.

A water-alternating-gas injection process can be implemented as hybrid WAG injection, in which a 
large volume of gas is initially injected, and then small volumes of water and gas are injected maintaining a WAG ratio of 1:1 (Arne and Elisabeth, 2007; Bunge and Radke, 1982; Christensen et al., 2001; Magruder et al., 1990; Prieditis et al., 1991; Roper et al., 1992). Moreover, simultaneous water and gas injection (SWAG) is also one of the well-known techniques (Ahmad et al., 2009; Arne and Elisabeth, 2007). Based on laboratory experiments, Caudle and Dyes proposed in 1958 that simultaneous water and gas injection can improve the displacement process. In a SWAG process, water and gas are injected simultaneously thereby providing the advantage of gas and water injection at the same time (Caudle and Dyes, 1958; Christensen et al., 2001).

\section{FACTORS INFLUENCING WAG PROCESS DESIGN}

The well-known issues to be considered in the design of the WAG process to date are fluid properties, rock-fluid interaction, availability and composition of injection gas, WAG ratio, heterogeneous permeability, injection pattern, capillary pressure, relative permeability, and wettability (Christensen et al., 2001; Heeremans et al., 2006; Lo et al, 2003; Raj et al., 2010; Rouzbeh and Larry, 2010; Morrow 1990), which are described below.

\subsection{Fluid properties and rock-fluid interaction}

Nowadays, highly precise measurements of fluid properties and characteristics can be done in laboratory (Florian et al., 2007; John and Reid, 2000; Sattar et al., 2007). But, unfortunately, the fluid behavior within the reservoir is a key parameter which still requires more knowledge and development for better understanding it. This phenomenon becomes even more complex when the prevailing conditions within the reservoir change as a result of undergoing processes. Variations in rock-fluid interaction with changing conditions in a reservoir result in wettability variations, which in turn affect flow parameters such as capillary pressure and relative permeability (Josephina et al., 2006; Katayoun and Ali, 2005; Mathew et al., 2005; Zahoor, 2011).

\subsection{Availability and composition of injection gas}

In the design of WAG processes, the availability of gas, in terms of quantity and composition, plays a vital role. Usually, the gas produced with oil from a reservoir is re-injected during the WAG process. Gas composition, in particular, is critical in WAG process design because it is a deciding parameter that determines whether the process is going to be miscible or immiscible under the prevailing conditions of pressure and temperature within the reservoir (Bon and Sarma, 2009; Jianwei et al., 2008).

\subsection{WAG ratio}

The WAG ratio is highly significant in WAG process design (Chen et al., 2010, Farshid et al, 2010). A WAG ratio of $1: 1$ is normally used in field applications. However, the WAG ratio strongly depends on reservoir's wettability and availability of the gas to be injected (Jackson et al., 1985; John and Reid, 2000). In general, it is preferable to inject higher gas volumes as compared to water in oil-wet reservoirs. The amount of volumes to be injected at the desired pressures strongly affects the cost of surface facilities, like compressors and pumps, which in turn strongly influences the WAG ratios due to economic constraints.

\subsection{Heterogeneous Permeability}

The vast majority of reservoirs have nonuniform pore size distribution with varying degrees of interconnectivity, giving rise to heterogeneous permeability. Sometimes the heterogeneity can be segregated in the form of layers, constituting homogeneous layers in the reservoir. As heterogeneity becomes more disordered, an even more complex reservoir fluid flow behavior is observed. Heterogeneity can severely affect WAG process design and resulting recovery rates. This situation worsens as the vertical-to-horizontal permeability ratio increases. As this ratio increases, gravity segregation start dominating the fluid flow behavior, which might result in lower recovery rates (John and Reid, 2000; Latil, 1980). The effect of vertical segregation was studied by Jackson et al. (1985), which concluded that the relationship between permeability ratio and oil recovery rates is of inverse proportions. 
The effects of stratification and heterogeneity can be distinct in different reservoirs, affecting various parameters such as capillary pressure, relative permeability, and mobility ratios (Ahmad et al., 2009; Al-Shuraiqi et al., 2003; Carlos et al., 2001; Farshid et al., 2010; Gorell, 1990; Henriquez et al., 1996; John and Reid, 2000; McCoy et al., 2000).

\subsection{Injection Pattern}

Well's spacing is critical in WAG process design (Christensen et al., 1998, 2001; Fanchi, 2004; Jensen et al., 1996; Mohammad et al., 2010; Nestor, 1999; Raj et al, 2010; Ridha, 2003; Skauge and Berg, 1997; Slotte et al., 1996). The Five-spot injection pattern is very popular, as it can provide better control on frontal displacement (Christensen et al. 1998, 2001; Fanchi, 2006; Latil, 1980; Talal and Joost, 2006). However, the results of a recent study conducted by Mohammad et al. (2010) on an Iranian fractured reservoir shows that a 4-spot pattern (4 producers with 2 injectors) gives higher recovery than a 5-spot pattern (6 producers with 2 injectors). Therefore, increasing the number of wells does not necessarily mean that recovery will be increased.

Well's orientation is also an important parameter, because combination of vertical producers with horizontal injectors is known to give better recovery (Chase and Todd, 1984; Nestor, 1999). The advances in computer technology and software development have made this possible, that the optimum location of wells and their orientation, together with parameters like WAG ratio, can be selected through simulation studies by preparing a number of scenarios (different field development models of reservoir) and analyzing the front propagation and recovery enhancement (Attanucci et al. 1993; Charles and Startzman, 1991; Farzaneh et al. 2009; Flores, 1982; Thu et al., 1983; Talal and Joost, 2006; Tara and Kristian, 2007; Todd and Asgarpour, 1988).

\subsection{Capillary pressure}

The capillary pressure is defined as the difference in pressure at the interface between two immiscible fluids. Mathematically, it can be expressed by Equation 1, for a system in which one fluid is wetting and the other is non-wetting:
$\mathrm{P}_{\mathrm{c}}=\mathrm{P}_{\mathrm{nw}}-\mathrm{P}_{\mathrm{w}}$

In terms of radius of the pore throat, the capillary pressure can be given by Equation 2, as discussed by Cosse (1993):

$\mathrm{P}_{\mathrm{c}}=\frac{2 \sigma \operatorname{Cos} \theta}{\mathrm{r}}$

where $\theta$ is the contact angle, representing rock wettability; and $\mathbf{r}$ is the radius of the pore's throat. The entry pressure, or the pressure at which the displacement of one fluid by another will start, can be estimated by modifying Equation (2) as follows:

$P_{d}=\frac{2 \sigma \operatorname{Cos} \theta}{R}$

where $\mathbf{R}$ is the radius of the largest pore in which the displacement process initiates.

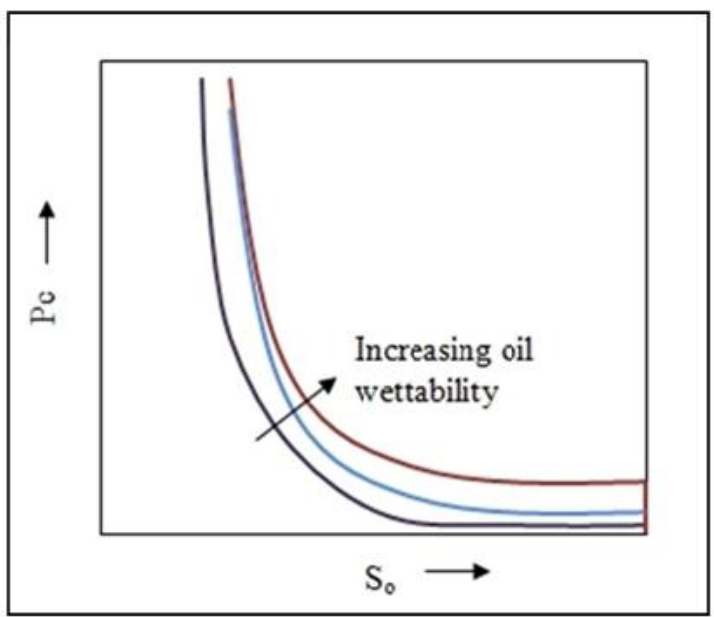

Figure 2. Capillary pressure curves under different wettability conditions.

Experiments conducted by Killins et al. (1953) showed that both displacement pressure and capillary pressure are comparatively high in strongly oil-wet rocks during displacement of a wetting phase by a non-wetting phase, which can be demonstrated with the help of Figure 2 (as a function of oil saturation, $\mathrm{S}_{\mathrm{o}}$ ).

This difference is due to the strong affinity of the rock surface with oil to become oil-wet, as compared to moderately or poorly oil-wet rocks. The difference in capillary pressure behavior and the degree of affinity between the rock surface and fluid (water and oil) play an important role in calculating the volumes of fluid to be injected, their 
composition (gas, brine, surfactants, etc.) and hence in the design of any enhanced oil recovery method (Chandra and Dandina, 2003). For example, in the case of WAG process in oil-wet reservoirs, if miscibility can be achieved, it will result in decreasing oil viscosity, also causing some part of oil which coats the rock surface to become mobile by overcoming the adhesive forces (the higher the adhesive forces, the higher the oilwetness of the rock), which will also be produced later at lower pressure differentials.

\subsection{Relative permeability}

Relative permeability is a direct measure of the ability of the porous system to conduct one fluid in the presence of one or more fluids (Craig, 1971). The relative permeability of a fluid is strongly dependent on wettability, as it controls the initial distribution of fluid and the further displacement of one fluid by another (Anderson, 1987a). The wetting phase occupies the smaller pores while the non-wetting phase retains the larger pores (Ahmed, 2006; Anderson, 1987a; Donaldson and Thomas, 1971; Peet, 2008). By occupying the smaller pores, the wetting phase will have lower relative permeability as compared to the nonwetting phase. This difference in permeability is due to the fact that the wetting phase will be travelling through tighter paths that have poor connectivity as compared to the paths mainly followed by the non-wetting phase (Ahmed, 2006; Anderson, 1987a). This can be illustrated with the help of Figure 3 , which shows that the relative permeability of oil or water is lower for the same saturation in its wetting state (see the Nomenclature section for details).

The effect of wettability and fluid distribution on displacement behavior in the porous medium can be best explained by assuming an oil-water and rock system. During water injection, when the rock surface is preferentially water-wet, water will advance along the walls of the pore, and the oil will be displaced quite easily because of weaker or no adhesive forces existing between oil and rock surfaces (Anderson, 1987a; Sattar et al., 2007). In contrast, under oil-wet situations, injected water preferably flows through less restrictive paths (larger pores), and the existing adhesive forces impair the oil flow, leaving higher remaining oil saturation at breakthrough as discontinuous ganglia and also coating the rock surface

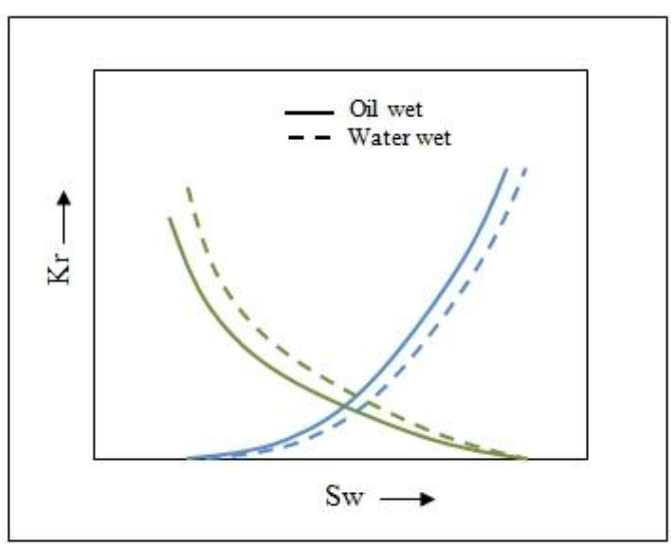

Figure 3. Relative permeability curves under different wettability conditions.

(Anderson, 1987a; Craig, 1971; Donaldson and Thomas, 1971; Sattar et al., 2007). This shows that water injection in a water-wet system is comparatively more efficient, resulting in higher oil recovery as compared to oil-wet situations (Anderson, 1987a; Morrow et al., 1986; Sattar et al., 2007). So, wettability needs to be considered crucially during WAG process design for even improved recovery.

Furthermore, the significance of capillarity can be represented by using a capillary number and further relating this number with recovery expectations. Mathematically, the capillary number $\left(N_{c}\right)$ can be given as (Rao et al., 2006):

$$
\mathrm{N}_{\mathrm{c}}=\frac{\mathrm{v} \mu}{\sigma \cos \theta}
$$

Where, Equation (4) shows that, as the capillary number decreases due to increase in capillarity ( $\sigma$ $\cos \theta$ ), the recovery decreases (Moore and Slobod, 1995; Sattar et al., 2007).

\subsection{Wettability}

Wettability is the ability of one fluid to coat the rock surface in the presence of other immiscible fluids (Craig, 1971). As discussed earlier, WAG process design parameters are directly or indirectly influenced by wettability. The design becomes further complicated when wettability can also change with time as a result of undergoing processes within the reservoir. A number of authors (Baldwin and Gray, 1974; Crocker and Marchin, 1985; Anderson, 1986; Dandekar, 2006; 
Donaldson and Thomas, 1971; Donaldson, 1981; Donnez, 2007; McGee, 1985; Tripathi and Mohanty, 2008) have discussed the causes of wettability alteration. Wettability can be different in different parts of the reservoir, due to distinct phenomena of adsorption and deposition of organic and inorganic materials present in the crude oil (Baldwin and Gray, 1974; Civan, 2000; Drummond and Israelachvili, 2004; Johansen and Dunning, 1959; Kowalewski et al., 2002; Morrow, 1990, Shedid and Ghannam, 2004). This also occurs due to the presence of diverse kind of minerals in different regions of the formation (Brown and Neustadter, 1980; Figdore, 1982; Gaudin and Fuerstenau, 1955; Liu and Buckley, 1999; Somasundaran and Hanna, 1979; Strand et al., 2006; Zhang and Austad, 2006, Zhang et al., 2007).

Organic materials can precipitate in a reservoir as a result of undergoing processes and corresponding changes in the prevailing conditions. After precipitation, these materials have the tendency to get deposited or adsorbed on the rock surface, affecting the formation wettability. The following correlation can be used to predict the extent of precipitation (Oddo and Tomson, 1994):

$$
\mathrm{F}_{\mathrm{s}}=\mathrm{x}_{\mathrm{A}} /\left(\mathrm{x}_{\mathrm{A}}\right)_{\mathrm{s}}
$$

Furthermore, the chances of precipitation of inorganic materials present in crude oil can be calculated by using the following correlation (Oddo and Tomson, 1994):

$$
\mathrm{F}_{\mathrm{s}}=\left[\mathrm{M}_{\mathrm{e}}\right]^{\mathrm{v}_{1}}\left[\mathrm{~A}_{\mathrm{n}}\right]^{\mathrm{v}_{2}} / \mathrm{K}_{\mathrm{sp}}
$$

where $F_{\mathrm{s}}<1$ stands for undersaturated solution, $F_{\mathrm{s}}$ $=1$ shows equilibrium stage, and $F_{s}>1$ represents supersaturated solutions, demonstrating that the conditions are favorable for precipitation.

Some studies have shown that reservoirs which were initially strongly water-wet can be changed to oil-wet as a result of adsorption of surface-active agents present in the crude oil (for example, asphaltenes, etc.) on the oppositely charged rock surfaces (Liu and Buckley, 1999; Dandekar, 2006). These agents can affect the wettability of sandstone as well as that of carbonate surfaces (Abdurashitove et al., 1996). Wettability alteration can also be a continuous process depending on the nature of deposition. Deposition of surface-active agents can be either static or dynamic. The latter differs in a way that the quantity of adsorbed asphaltenes continuously increases, which may also lead to formation damage (Piro et al., 1996; Stephen et al., 2006). It has been reported in the literature survey by Dandekar (2006) that wettability can be altered as a result of asphaltene adsorption from a contact angle of $40-60^{\circ}$ to $120^{\circ}$, and also from $50-70^{\circ}$ to $170^{\circ}$.

\section{RECENT DEVELOPMENTS}

Due to the advances in computer technology, with ready availability of reservoir simulation softwares, the design of WAG or any other enhanced oil recovery process is accomplished with the help of dynamic modeling. These advancements gives the opportunity for reservoir analysts to choose from several options, such as analyzing different well injection patterns, WAG ratios, injection rates, etc. Also, the optimum design could then be selected in a time-efficient manner, based on economic constraints and company's policies. For precise and more reliable studies, better knowledge on fluid flow behavior within the reservoir is required, which is strongly influenced by wettability and parameters that depend on wettability, particularly capillary pressure and relative permeability (Kim et al., 1990; Zahoor, 2011). To accomplish the desired task, efforts have been made from time to time for better incorporation of wettability effects on reservoir's dynamics. Special consideration has been given in obtaining the capillary pressure curves, which are truly representative of the reservoir. Once capillary pressure curves are obtained, they can then be used to generate relative permeability data at prevailing conditions of wettability, using relative permeability models available in the industry.

A model presented by Anderson (1987b) shows the behavior of the capillary pressure curve with reference to displacement of one fluid by another in a core. Later, Tsakiroglou and Fleury (1999) developed the model to generate capillary pressure curves for fractionally-wet rocks, based on water saturation regions. Also, a set of correlations have been recently developed by Zahoor (2011), which can successfully generate and predict capillary pressure curves for the entire range of 
wettability conditions, i.e., from strongly water-wet to strongly oil-wet situations.

\subsection{Zahoor Correlation}

A set of correlations have been developed by Zahoor (2011) to predict capillary pressure for the entire range of wettability conditions, provided that the capillary pressure data set for any wettability condition is known. Mathematically, in a generalized form:

$P_{c . e s t .}=P_{d_{b, c}}\left(S_{e m}\right)^{-1 / \lambda} \pm k_{1}(\Delta \theta) \times P_{d_{b, c}} \times\left(S_{e m}\right)^{-1 / \lambda}$

where $\mathbf{k}_{\mathbf{1}}=1.24 \times 10^{-4}$ and $\mathbf{S}_{\mathrm{em}}$ is a parameter that is based on the saturation stage, taking place during the displacement process (Zahoor, 2011).

The sign convention in the correlation, in general, will be positive if the capillary pressure is to be predicted for wettability in increasing order (in terms of contact angle) and the displaced fluid is oil. To generate a capillary pressure curve, the entire displacement process can be divided into three parts, as follows:

1) Displacement at higher displaced fluid saturation stage

2) Displacement at lower displaced fluid saturation stage

3) Transient stage

\subsubsection{Flow at higher displaced fluid saturation}

To predict the capillary pressure during this stage, effective mobile phase saturation can be given as:

$$
\mathrm{S}_{\mathrm{em}}=\frac{\mathrm{S}_{\text {mphasel }}-\mathrm{S}_{\text {rmphasel }}}{1-\mathrm{S}_{\text {rmphase } 2}-\mathrm{S}_{\text {rmphasel }}}
$$

Equation 10 gives a good prediction of capillary pressure for the flow at higher displaced fluid saturation stage (H.S.S), which is obtained by incorporating Equation 9 into the developed correlation (Equation 8) for capillary pressure estimation. Mathematically:

$$
\begin{aligned}
& \mathrm{P}_{\text {c.est. }}=\mathrm{P}_{\mathrm{d}_{\mathrm{b} . \mathrm{c}}}\left(\frac{\mathrm{S}_{\text {mphasel }}-\mathrm{S}_{\text {rmphase1 }}}{1-\mathrm{S}_{\text {rmphase } 2}-\mathrm{S}_{\text {rmphasel }}}\right)^{-1 / \lambda} \pm \\
& \pm \mathrm{k}_{1}(\Delta \theta) \times \mathrm{P}_{\mathrm{d}_{\mathrm{b} . \mathrm{c}}} \times\left(\frac{\mathrm{S}_{\text {mphasel }}-\mathrm{S}_{\text {rmphasel }}}{1-\mathrm{S}_{\text {rmphase } 2}-\mathrm{S}_{\text {rmphase }}}\right)^{-1 / \lambda}
\end{aligned}
$$

In simplified notations, this stage finishes at approximately $43.75 \%$ of the maximum displaced phase saturation. During this stage, trapping of displaced fluid (oil or water), adhesive forces and roughness of rock surface do not have significant impacts because higher saturation is available for displacement during the initial stage of the process. Therefore, changes in capillary pressure, with reference to saturation, are comparatively less intensive.

\subsubsection{Flow at lower displaced fluid saturation}

This stage occurs when the displaced fluid saturation is approaching its residual saturation after transient flow. In this lower displaced fluid saturation stage (L.S.S), any further decrease in the saturation of the displaced fluid results in abrupt changes in capillary pressure with reference to change in saturation. Briefly, during this stage, a significant increase in pressure is required to displace the fluid further to lower saturation levels, when the discontinuous ganglia of displaced fluid are re-uniting, which are produced later. To estimate the capillary pressure during this stage, the effective mobile phase saturation can be given as:

$$
\mathrm{S}_{\mathrm{em}}=\frac{\mathrm{S}_{\mathrm{mphasel}}-\mathrm{S}_{\text {rmphasel }}}{1-\mathrm{S}_{\text {rmphasel }}}
$$

In this case, the developed correlation (Equation 8) for capillary pressure estimation becomes:

$$
P_{c \text { cest. }}=P_{\mathrm{d}_{\mathrm{b} . c}}\left(\frac{\mathrm{S}_{\text {mphasel }}-\mathrm{S}_{\text {rmphasel }}}{1-\mathrm{S}_{\text {rmphasel }}}\right)^{-1 / \lambda} \pm \mathrm{k}_{1}(\Delta \theta) \times \mathrm{P}_{\mathrm{d}_{\mathrm{b} . \mathrm{c}}} \times\left(\frac{\mathrm{S}_{\text {mphasel }}-\mathrm{S}_{\text {rmphasel }}}{1-\mathrm{S}_{\text {mphasel }}}\right)^{-1 / \lambda}
$$

\subsubsection{Transient stage}

This stage lies between the two stages mentioned above. During this period, capillary pressure increases rapidly with small changes in the displaced fluid saturation, as compared to flow during the displacement at higher displaced phase saturation stage. This flow stage occurs for a further $10 \%$ change (approximately) in the displaced fluid saturation, after the H.S.S. stage is finished. It is observed that the average of 
estimated capillary pressure for the stages mentioned above gives a good prediction of capillary pressure during this stage. Mathematically:

$$
\mathrm{P}_{\text {c.est.(Transient stage) }}=\frac{\mathrm{P}_{\text {c.est.(H.S.S) }}+\mathrm{P}_{\text {c.est.(L.S.S })}}{2}
$$

The data generated by this methodology can be incorporated into simulation studies. Knowledge of the degree of affinity between the rock surface and the oil/water interface more precisely facilitate the proper design for WAG process or any other enhanced oil recovery process.

\section{CONCLUSION}

WAG process design is comparatively more crucial in the case of oil-wet reservoirs as compared to water-wet situations, due to higher remaining oil saturation. In addition, the higher volumes of trapped oil enhance its feasibility for field scale implementation. Proper WAG process design and implementation requires better knowledge on wettability, and wettability variations in particular. Wettability, in addition to influencing flow parameters, strongly affects other design parameters, like the volumes of water and gas required for injection, well spacing, etc. Therefore, when the effect of wettability and its variations within a reservoir during different stages of depletion can be estimated precisely, an improved WAG process design can be made in a time-efficient and cost-effective manner.

\section{NOMENCLATURE}

$\begin{array}{ll}A_{n} & \text { anion present in inorganic material } \\ F_{s} & \text { saturation ratio } \\ K_{s p} & \text { saturation solubility product } \\ K_{r} & \text { relative permeability } \\ M_{e} & \text { cation present in inorganic material } \\ P_{c} & \text { capillary pressure } \\ P_{c . e s t .} & \text { estimated capillary pressure } \\ P_{d b . c} & \text { displacement pressure of base case } \\ P_{n w} & \text { pressure of non-wetting phase } \\ P_{w} & \text { pressure of wetting phase } \\ P_{d} & \text { displacement or entry pressure } \\ r & \text { pore throat radius }\end{array}$

$\mathrm{S}_{\mathrm{em}} \quad$ effective mobile phase saturation

$\mathrm{S}_{\mathrm{O}} \quad$ oil saturation

$S_{\text {mphase1 }}$ mobile phase saturation of fluid 1

$\mathrm{S}_{\text {rmphase1 }}$ mobile phase residual saturation of fluid 1

$\mathrm{S}_{\text {rmphase2 }}$ residual saturation of fluid 2

$\checkmark \quad$ velocity of displacing phase

$v_{1}, v_{2} \quad$ stoichiometric coefficients

$\mathrm{x}_{\mathrm{A}} \quad$ mole fraction of dissolved organic

$\left(x_{A}\right)_{S} \quad$ organic solubility at saturation conditions

$\Delta \quad$ difference

$\sigma \quad$ surface or interfacial tension, between two immiscible fluids

$\theta \quad$ contact angle

$\mu \quad$ viscosity

$\lambda \quad$ characteristic constant

\section{REFERENCES}

Abdurashitov, S. A.; Guesinov, M. F.; Tairov, N. D. Effect of different rock fractions upon the adsorption of asphaltenes from petroleums of the balakhanysabunchi-ramaninsk deposits, Isv. Vyssh. Ucheb. Zaved, v.9 (10), p. 63-65, 1996.

Ahmad, F.; Kevin, B.; Bauyrzhan, Z.; Ali, M. Z.; William, R. R. Injectivity and gravity segregation in WAG and SWAG enhanced oil recovery. SPE Annual Technical Conference and Exhibition. New Orleans, Louisiana: Society of Petroleum Engineers. 2009. 124197-MS.

Ahmed, T. Reservoir engineering handbook. Oxford: Elsevier Inc., 2006.

Al-Shuraiqi, H. S.; Muggeridge, A. H.; Grattoni, C. A. Laboratory investigations of first contact miscible WAG displacement: The effects of WAG ratio and flow rate. SPE International Improved Oil Recovery Conference in Asia Pacific, 2003, Kuala Lumpur, Malaysia: Society of Petroleum $\quad 2003 . \quad$ 8ngineers. doi:10.2118/84894-MS

Anderson, W. G. Wettability Literature Survey - Part 1: Rock/Oil/Brine Interactions and the Effects of Core Handling on Wettability. SPE Journal of Petroleum Technology, v. 38 (10), p. 1125-1144, 1986.

Anderson, W. G. Wettability literature survey - Part 5: The effects of wettability on relative permeability. SPE Journal of Petroleum Technology, v.39 (11), p. 14531468, 1987. 
Anderson, W. G. Wettability literature survey - Part 4: Effects of wettability on capillary pressure. SPE Journal of Petroleum Technology, v.39 (10), p. 12831300, 1987.

Arne, S.; Elisabeth, I. D. Progress in immiscible WAG modelling. SPE/EAGE Reservoir Characterization and Simulation Conference. Abu Dhabi, UAE: Society of Petroleum Engineers. 2007. 111435-MS.

Attanucci, V.; Aslesen, K. S.; Hejl, K. A.; Wright, C. A. WAG process optimization in the Rangely $\mathrm{CO}_{2}$ miscible flood. In SPE Annual Technical Conference and Exhibition. Houston, Texas, 1993, Society of Petroleum Engineers, Inc. doi:10.2118/26622-MS

Baldwin, B. A.; Gray, P. R. Fluid-Surface interactions in oil reservoirs: Society of Petroleum Engineers, 1974.

Bon, J.; Sarma, H. K. Investigation of the effect of injection gas composition on $\mathrm{CO}_{2}$-rich flooding and its implications in an onshore Australia oilfield. Canadian International Petroleum Conference. Calgary, Alberta: Petroleum Society of Canada. 2009, 2009-139.

Brown, C. E.; Neustadter, E. L. The wettability of oil/water/silica systems with reference to oil recovery. J. Can. Pet. Technology, v.19, p. 100-110, 1980.

Bunge, A. L.; Radke, C. J. $\mathrm{CO}_{2}$ flooding strategy in a communicating layered reservoir. SPE Journal of Petroleum Technology, v.34 (12), p. 2746-2756, 1982.

Carlos, A.; Eduardo, M.; Vladimir, A.; Adnan, S.; Leonid, S.; Terje, E. WAG pilot at VLE field and IOR opportunities for mature fields at Maracaibo Lake. In SPE Asia Pacific Improved Oil Recovery Conference. Kuala Lumpur, Malaysia, 2001, Society of Petroleum Engineers Inc. 72099. doi:10.2118/72099-MS

Caudle, B. H.; Dyes, A. B. Improving miscible displacement by gas-water injection, 1958, Society of Petroleum Engineers, 911-G.

Chandra, S. V.; Dandina, N. R. Effect of brine dilution and surfactant concentration on spreading and wettability. In International Symposium on Oilfield Chemistry. Houston, Texas, 2003, Society of Petroleum Engineers. 80273-MS.

Charles, D. D.; Startzman, B. A. Streamtube modeling of horizontal wells in mixed pattern waterfloods. In SPE Eastern Regional Meeting. Lexington, Kentucky, 1991, Society of Petroleum Engineers, Inc. 23451-MS.

Chase Jr, C. A.; Todd, M. R. Numerical Simulation of $\mathrm{CO}_{2}$ flood performance. (includes associated papers 13950 and 13964 ). SPE Journal, v.24 (6), p. 597-605, 1984.
Chen, S.; Li, H.; Yang, D.; Tontiwachwuthikul, P. Optimal parametric design for water-alternating-gas (WAG) process in a $\mathrm{CO}_{2}$-miscible flooding reservoir. Journal of Canadian Petroleum Technology. v.49 (10), p. 75-82, 2010. doi:10.2118/141650-PA

Christensen, J. R.; Stenby, E. H., Skauge, A. Review of WAG field experience. In International Petroleum Conference and Exhibition of Mexico. Villahermosa, Mexico, 1998, Society of Petroleum Engineers, Inc., 39883-MS. doi:10.2118/39883-MS

Christensen, J. R.; Stenby, E. H., Skauge, A. Review of WAG field experience. SPE Reservoir Evaluation \& $\begin{array}{lllll}\text { Engineering, } & \text { v.4 } & \text { (2), p. } & \text { 97-106, } 2001 .\end{array}$ doi:10.2118/71203-PA

Civan, F. Reservoir formation damage: fundamentals, modelling, assessment and mitigation. Houston: Gulf Publishing Company. 2000.

Cosse, R. Oil and gas field development techniques Basics of reservoir engineering. Houstan, Texas, U.S.A: Gulf Publishing Company, 1993.

Craig, F. F. The reservoir engineering aspects of waterflooding. TX: Monograph Series, SPE, Richardson, 1971.

Dandekar, A. Y. Petroleum reservoir rock and fluid properties. Florida: CRC Press, Taylor \& Francis Group, 2006.

Dehghan, A.; Farzaneh, S.; Kharrat, R.; Ghazanfari, M.; Rashtchian, D. Pore-level investigation of heavy oil recovery during water alternating solvent injection process. Transport in Porous Media, v.83 (3), p. 653666,2009 . doi:10.1007/s11242-009-9463-5

Donaldson, E.C. Oil-water-rock wettability measurements. American Chemical Soc., div. of Petroleum Chemistry, v.26 (1), p. 110-122, 1981.

Donaldson, E. C.; Thomas, R. D. Microscopic observations of oil displacement in water-wet and oilwet systems. In Fall Meeting of the Society of Petroleum Engineers of AIME. New Orleans, Louisiana, 1971. 3555MS.

Donnez, P. Essentials of reservoir engineering. Paris: Editions Technip. 2007.

Drummond, C.; Israelachvili, J. Fundamental studies of crude oil-surface water interactions and its relationship to reservoir wettability. Journal of Petroleum Science and Engineering, v.45 (1-2), p. 61-81, 2004. doi:10.1016/j.petrol.2004.04.007 
Fanchi, J. R. Energy: Technology and directions for the future. London: Elsevier Academic Press. 2004.

Fanchi, J. R. Principles of applied reservoir simulation. 3rd. ed. New York: Gulf Professional Publishing, 2006.

Farshid, T.; Benyamin, Y. J.; Ostap, Z.; Brett, A. P.; Nevin, J. R.; Ryan, R. W. Effect of oil viscosity, permeability and injection rate on performance of waterflooding, $\mathrm{CO}_{2}$ flooding and WAG processes on recovery of heavy oils. Canadian Unconventional Resources and International Petroleum Conference. 2010, Calgary, Alberta, Canada: Society of Petroleum Engineers, 138188-MS.

Farzaneh, S. A.; Dehghan, A. A.; Kharrat, R.; Ghazanfari, M. H. A comparative study of was, swas and solvent-soak scenarios applied to heavy oil reservoirs using 5-spot glass micromodels. In Canadian International Petroleum Conference. Calgary, Alberta, 2009, Petroleum Society of Canada, 2009-038. doi:10.2118/2009-038

Figdore, P. E. Adsorption of Surfactants on Kaolinite: $\mathrm{NaCl}$ versus $\mathrm{CaCl}_{2}$ Salt Effects. J. Colloid Interface Science, v.87 (2), p. 500-517, 1982. doi:10.1016/00219797(82)90347-2

Flores, J. Development and reservoir engineering studies for the Pulai field Offshore Peninsular Malaysia. In Offshore South East Asia Show. Singapore, 1982. 10472-MS

Florian, H.; Bruno, G. P.; Jing, J. Z.; Vlamir, B.; Emmanuel, D. An innovative multiphase sampling solution at the well site to improve multiphase flow measurements and phase behavior characterization. International Petroleum Technology Conference. 2007, Dubai, U.A.E.: International Petroleum Technology Conference. 2007. 11573-MS.

Freistuhler, H.; Warnecke, G. Hyperbolic problems: Theory, numerics, applications. Berlin: Birkhauser, 2000.

Gaudin, A. M.; Fuerstenau, D. W. Quartz flotation with An-ionic collectors. Trans., AIME - Mining Engineering, v.202, p. 66-72, 1955.
Gorell, S. B. Implications of water-alternate-gas injection, for profile control and injectivity. In SPE/DOE Enhanced Oil Recovery Symposium. Tulsa, Oklahoma, 1990, Society of Petroleum Engineers, Inc. 20210-MS. doi:10.2118/20210-MS

Heeremans, J. C.; Esmaiel, T. E.; Kruijsdijk, C. P. J. W. Feasibility study of WAG injection in naturally fractured reservoir. In Symposium on Improved Oil Recovery. Tulsa, 2006. Society of Petroleum Engineers, Inc. 100034-MS.

Henriquez, A.; Jourdan, C. A. Management of sweepefficiency by gas-based IOR methods. In European Petroleum Conference. Milan, Italy, 1996, Society of Petroleum Engineers, Inc. 36843-MS.

Ho, C. K.; Webb, S. W. Gas transport in porous media. Dordrecht: Springer. 2006. doi:10.1007/1-4020$\underline{3962-X}$

Hyne, N. J. Nontechnical guide to petroleum geology, exploration, drilling and production. 2nd. ed. Tulsa: PennWell Corporation. 2001.

Jackson, D. D.; Andrews, G. L.; Claridge, E. L. Optimum WAG ratio vs. rock wettability in $\mathrm{CO}_{2}$ flooding. In SPE Annual Technical Conference and Exhibition. Las Vegas, Nevada, 1985, Society of Petroleum Engineers. 14303-MS. doi:10.2118/14303-MS

Jensen, J.; Nesteby, H.; Slotte, P. A. B. WAG pilot. Stavanger: Norwegian Petroleum Directorate, 1996.

Jensen, T. B.; Harpole, K. J.; Ëœsthus, A. EOR Screening for Ekofisk. In SPE European Petroleum Conference. Paris, France, 2000, Society of Petroleum Engineers Inc. 65124. doi:10.2118/65124-MS

Jianwei, W.; Joseph, A.; Duane, M.; Walter, B. A. Evaluation of reservoir connectivity and development recovery strategies in Monument Butte field, Utah. SPE Annual Technical Conference and Exhibition. 2008. Denver, Colorado, USA: Society of Petroleum Engineers. 116695-MS.

Jianwei, W.; Duane, A. M.; Walter, B. A. Compositional simulation and optimization of secondary and tertiary recovery strategies in Monument Butte field, Utah. SPE Eastern Regional/AAPG Eastern Section Joint Meeting. 2008. Pittsburgh, Pennsylvania, USA: Society of Petroleum Engineers. 117775-MS. 
Johansen, R. T.; Dunning, H. N. Relative wetting tendencies of crude oil by the capillarimetric method. Producers Monthly, v.23 (11), p. 20-22, 1959.

John, D. R.; Reid, B. G. A literature analysis of the WAG injectivity abnormalities in the $\mathrm{CO}_{2}$ process. In SPE/DOE Improved Oil Recovery Symposium. Tulsa, Oklahoma, 2000, Society of Petroleum Engineers. 59329-MS.

Josephina, M. S.; Guo-Qing, T; Anthony, R. K. Interrelationship of temperature and wettability on the relative permeability of heavy oil in diatomaceous rocks (includes associated discussion and reply). SPE Reservoir Evaluation \& Engineering, v.9 (3), p. 239-250, 2006.

Katayoun, S. N.; Ali, D. Visual investigation of oil depressurisation in pores with different wettability characteristics and saturation histories. SPE Europec/EAGE Annual Conference. 2005, Madrid, Spain: Society of Petroleum Engineers. SPE 94054

Killins, C. R.; Nielsen, R. F.; Calhoun, J. C. Capillary desaturation and imbibition in porous rocks. Producers Monthly, v.18 (2), p. 30-39, 1953.

Kim, S. T.; Boudh-Hir, M. E.; Mansoori, G. A. The role of asphaltene in wettability reversal. SPE Annual Technical Conference and Exhibition. 1990, New Orleans, Louisiana: SPE 20700. doi:10.2118/20700-MS

Kowalewski, E.; Holt, T.; Torsaeter, O. Wettability alterations due to an oil soluble additive. Journal of Petroleum Science and Engineering, v.33 (1-3), p. 19-28, 2002. doi:10.1016/S0920-4105(01)00172-3

Latil, M. Enhanced oil recovery. Houston. Gulf Publishers, 1980.

Liu, L.; Buckley, J. S. Alteration of wetting of mica surfaces. Journal of Petroleum Science and Engineering, v.24 (2-4), p. 75-83, 1999. doi:10.1016/S0920$\underline{4105(99) 00050-9}$

Lo, L. L.; McGregor, D. S.; Wang, P.; Boucedra, S.; Bakhoukhe, C. WAG pilot design and observation well data analysis for Hassi Berkine South field. SPE Annual Technical Conference and Exhibition. 2003. Denver, Colorado: Society of Petroleum Engineers. 84076-MS. doi:10.2118/84076-MS
Magruder, J. B.; Loren, H. S.; Thomas, D. Y. Review of the Means San Andres Unit $\mathrm{CO}_{2}$ Tertiary Project. SPE Journal of Petroleum Technology, v.42 (5), p. 638-644, 1990.

Mathew, D. J.; Per, H. V.; Martin, J. B. Prediction of wettability variation within an oil/water transition zone and its impact on production. SPE Journal, v.10 (2), p. 185-195, 2005.

McCoy, T. F.; Reese, D. E.; Johnson, P. G. Depletion performance of poorly stimulated layered reservoirs without crossflow. In SPE/CERI Gas Technology Symposium. Calgary, Alberta, Canada, 2000, Society of Petroleum Engineers Inc. 59757-MS. doi:10.2118/59757$\underline{\mathrm{MS}}$

McGee, J.; Crocker, M. E.; Marchin, L.M. Wettability: State-of-the-art. A review of the literature. Bartlesville. Natl. Inst. for Petroleum Research, 1985.

Mohammad, J. D.; Babak, M.; Ghassem, Z.; Afshin, J.; Gholam, H. M. Study of various water alternating gas injection methods in 4- and 5-spot injection patterns in an Iranian fractured reservoir. Trinidad and Tobago Energy Resources Conference. 2010. Port of Spain, Trinidad: Society of Petroleum Engineers. 132847-MS.

Moore, T. F.; Slobod, R. L. The effect of viscosity and capillarity on the displacement of oil by water. Producers Monthly, August 1995.

Morrow, N. R.; Lim, H. T.; Ward, J. S. Effect of CrudeOil-Induced Wettability Changes on Oil Recovery. SPE Formation Evaluation, v.1 (1), p. 89-103, 1986. doi:10.2118/13215-PA

Morrow, N. R. Wettability and its effect on oil recovery. SPE Journal of Petroleum Technology, v.42 (12), p. 1476-1484, 1990.

Nestor, L. S. Management of water alternating gas (WAG) injection projects. Latin American and Caribbean Petroleum Engineering Conference. Caracas, Venezuela: Society of Petroleum Engineers. 1999. 53714-MS.

O'Carroll, D. M.; Abriola, L. M.; Polityka, C. A.; Bradford, S. A.; Demond, A. H. Prediction of two-phase capillary pressure-saturation relationships in fractional wettability systems. Journal of Contaminant Hydrology. v.77 (4), p. 247-270, 2005. doi:10.1016/i.jconhyd.2005.01.004 
Oddo, J. E; Tomson, M. B. Why Scale Forms in the Oil Field and Methods To Predict It. SPE Production \& Operations. v.9 (1), p. 47-54, 1994.

Peet, D.-J. Geotechnology and sustainable developments: challenges for the future. Delft: Uitgeverij Eburan. 2008.

Piro, G.; Canonico, L. B.; Galbariggi, G.; Bertero, L.; Carniani, C. Asphaltene Adsorption onto formation rock: An approach to asphaltene formation damage prevention. SPE Production \& Operations, v.11 (3), p. 156-160, 1996.

Prieditis, J.; Wolle, C. R.; Notz, P. K. A laboratory and field injectivity study: $\mathrm{CO}_{2}$ WAG in the San Andres formation of West Texas. In SPE Annual Technical Conference and Exhibition. Dallas, Texas, 1991, Society of Petroleum Engineers, Inc. 22653-MS. doi:10.2118/22653-MS

Raj, D. T.; Slamet, R.; Charles, K.; Farihan, A. K.; Mohamad, A. B.; Tengku, R. T. O.; Nazrin, B. Maximizing the oil recovery through immiscible water alternating gas (IWAG) in mature offshore field. SPE Asia Pacific Oil and Gas Conference and Exhibition. 2010. Brisbane, Queensland, Australia: Society of Petroleum Engineers. 133345-MS.

Rao, D. N.; Ayirala, S. C.; Abe, A. A.; Xu, W. Impact of low-cost dilute surfactants on wettability and relative permeability. SPE/DOE Symposium on Improved Oil Recovery. 2006. Tulsa, Oklahoma, USA: 99609-MS. doi:10.2118/99609-MS

Ridha, B. C. G. Integrated reservoir simulation studies to optimize recovery from a carbonate reservoir. SPE Asia Pacific Oil and Gas Conference and Exhibition. Jakarta, Indonesia: Society of Petroleum Engineers. 2003. 80437-MS.

Roper Jr, M. K.; Cheng, C. T.; Varnon, J. E.; Pope, G. A.; Kamy, S. Interpretation of a $\mathrm{CO}_{2}$ WAG injectivity test in the San Andres formation using a compositional simulator. In SPE/DOE Enhanced Oil Recovery Symposium. Tulsa, Oklahoma, 1992, Society of Petroleum Engineers Inc. 24163-MS.

Rouzbeh, G. M.; Larry, W. L. Simultaneous watergas-injection performance under loss of miscibility. SPE Improved Oil Recovery Symposium. 2010. Tulsa, Oklahoma, USA: Society of Petroleum Engineers. 129966-MS.
Sattar, A.; Iqbal, G. M.; Buchwalter, J. L. Practical enhanced reservoir engineering: Assisted with simulation software. Tulsa: PennWell Corporation. 2007.

Shedid, S. A.; Ghannam, M. T. Factors affecting contact-angle measurement of reservoir rocks. Journal of Petroleum Science and Engineering. v.44 (3-4), p. 193-203, 2004. doi:10.1016/i.petrol.2004.04.002

Skauge, A.; Berg, E. Immiscible WAG injection in the Fensfjord formation of the Brage oil field. In European Symposium on Improved Oil Recovery, 1997, Society of Petroleum Engineers Inc. 104.

Slotte, P.A.; Stenmark, H.; Aurdal, T. Snorre WAG pilot. Stavanger: Norwegian Petroleum Directorate, 1996.

Soares, C. Gas Turbines: A handbook of air, land and sea applications. London: Elsevier Inc. 2008.

Sohrabi, M.; Tehrani, D. H.; Danesh, A.; Henderson, G. D. Visualization of Oil Recovery by Water-AlternatingGas Injection Using High-Pressure Micromodels. SPE Journal. v.9 (3), p. 290-301, 2004. doi:10.2118/89000-PA

Somasundaran, P.; Hanna, H. S. Adsorption of sulfonates on reservoir rocks. SPE Journal, v.19 (4), p. 221-232, 1979.

Stephen, C. L.; Enzo, P.; Luca, M.; Franco, A. Development and field use of a novel solvent water emulsion for the removal of asphaltene deposits in fractured carbonate formations. SPE Annual Technical Conference and Exhibition. 2006. San Antonio, Texas, USA: Society of Petroleum Engineers. 101022-MS.

Strand, S.; Høgnesen, E. J.; Austad, T. Wettability alteration of carbonates-effects of potential determining ions ( $\mathrm{Ca} 2+$ and $\mathrm{SO}_{4} 2-$ ) and temperature. Colloids and Surfaces A: Physicochemical and Engineering Aspects, v.275 (1-3), p. 1-10, 2006. doi:10.1016/i.colsurfa.2005.10.061

Talal, E. E.; Joost, C. H. Optimization of the WAG process under uncertainty in a smart wells environment: Utility theory approach. Intelligent Energy Conference and Exhibition. 2006. Amsterdam, The Netherlands: Society of Petroleum Engineers. 100009-MS. 
Tara, C. L.; Kristian, J. Analytical and numerical investigation of multicomponent multiphase WAG displacements. SPE Annual Technical Conference and Exhibition. 2007. Anaheim, California, U.S.A.: Society of Petroleum Engineers. 110264-MS.

Thu, G. S.; Heacock, D. W.; Loveless, D. E. Exploration, development, and reservoir engineering studies for the Tapis field Offshore Peninsular Malaysia. SPE Journal of Petroleum Technology, v.35 (6), p. 10511060, 1983.

Todd, M. R.; Asgarpour, S. Simulation study and technical evaluation of the Fenn-Big Valley South Lobe (D-2A) hydrocarbon miscible flood. In Annual Technical Meeting. Calgary, Alberta, 1988, Petroleum Society of Canada. 88-39-38. doi:10.2118/88-39-38

Tripathi, I.; Mohanty, K. K. Instability due to wettability alteration in displacements through porous media. Chemical Engineering Science. v.63 (21), p. 5366-5374. 2008. doi:10.1016/j.ces.2008.07.022

Tsakiroglou, C. D.; Fleury, M. Resistivity index of fractional wettability porous media. Journal of
Petroleum Science and Engineering, v.22 (4), p. 253 274, 1999. doi:10.1016/S0920-4105(98)00085-0

Willhite, G. P. Enhanced oil recovery: Richardson. Society of Petroleum Engineers, 1986.

Zahoor, M. K. Predicting effects of wettability variations on displacement behavior and their incorporation into inflow performance. Doctoral Thesis, Universiti Teknologi Malaysia, 2010.

Zhang, P.; Austad, T. Wettability and oil recovery from carbonates: Effects of temperature and potential determining ions. Colloids and Surfaces A: Physicochemical and Engineering Aspects. v.279 (1-3), p. 179-187, 2006. doi:10.1016/i.colsurfa.2006.01.009

Zhang, P.; Tweheyo, M. T.; Austad, T. Wettability alteration and improved oil recovery by spontaneous imbibition of seawater into chalk: Impact of the potential determining ions $\mathrm{Ca} 2+, \mathrm{Mg} 2+$, and $\mathrm{SO}_{4} 2-$. Colloids and Surfaces A: Physicochemical and Engineering Aspects. v.301 (1-3), p. 199-208, 2007. doi:10.1016/i.colsurfa.2006.12.058 